\title{
Olive leaf phenolics and cardiovascular risk reduction: Physiological effects and mechanisms of action
}

\author{
Stacey Lockyer, Parveen Yaqoob, J.P.E. Spencer and Ian Rowland* \\ Hugh Sinclair Unit of Human Nutrition, Department of Food and Nutritional Sciences, School of Chemistry \\ Food and Pharmacy, University of Reading, Reading, UK
}

\begin{abstract}
Olive oil, an important component of the Mediterranean diet, is rich in polyphenols and is known to possess positive health effects relative to other dietary fats. In addition, the leaves of the olive plant (Olea europaea) contain similar phenolics (oleuropein, luteolin-7-glucoside, apigenin-7-glucoside, verbascoside and hydroxytyrosol) to those of olives and olive oil, although at higher concentrations. For example, the most abundant is the secoiridoid, oleuropein, representing 1-14\% of olive leaf weight vs. $0.005-0.12 \%$ in olive oil. Although currently considered a waste product of the olive oil industry, recent research has suggested beneficial effects of phenolic-rich olive leaf extracts (OLE) in modifying cardiovascular risk biomarkers such as blood pressure, hyperglycaemia, oxidative stress and inflammation, as well as improving vascular function and lipid profiles. Despite this, data regarding the biological actions of OLE has mostly derived from animal, in vitro and ex vivo studies, with limited evidence deriving from human trials. Although the absorption and metabolism of olive oil phenolics has been investigated, less is known about the bioavailability of phenolics from OLE, limiting the interpretation of existing in vitro and ex vivo data. The current review will begin by describing the phenolic composition of olive leaves in comparison with that of the better studied olive oil. It will then review the effects of OLE on cardiovascular risk factors, covering both animal and human studies and will end by considering potential mechanisms of action.
\end{abstract}

Keywords: Olive leaf, olive leaf extract, olive phenolics, cardiovascular disease

\section{Introduction}

Epidemiological evidence has suggested that a high consumption of olive oil, a major fat component of the Mediterranean diet, is associated with a reduced risk of coronary heart disease, obesity, metabolic syndrome, type 2 diabetes, cancer and cognitive disorders $[1,2]$. Indeed, such evidence has led to a health claim being permitted by the US Food and Drug Administration relating to the consumption of 2 tablespoons

${ }^{*}$ Corresponding author: Prof. Ian Rowland, Department of Food and Nutritional Sciences, University of Reading, Reading RG6 6AP, UK. Tel.: +44 0118378 8702; Fax: +44 0118931 0080; E-mail: i.rowland@reading.ac.uk.
(23 grams) of olive oil daily and a reduction in coronary heart disease risk [1]. It was previously believed that the health benefits of olive oil consumption were solely due to its monounsaturated fatty acid (MUFA) content, particularly oleic acid [3]. However, other edible oils rich in MUFA have not always been observed to possess similar health promoting properties $[4,5]$, and biological effects of various polyphenolic compounds contained in the water soluble fraction of olive oil have been reported [6].

Polyphenols are naturally occurring secondary metabolites found ubiquitously in plants. Their functions within plants include: aiding growth and reproduction, providing defence against pathogens and insects and protecting against environmental stressors, 
<smiles>C/C=C1\[C@@H](OC2O[C@H](C)[C@@H](O)[C@@H](O)[C@@H]2O)OC=C(C(=O)OC)[C@@H]1CC(=O)OCCc1ccc(O)c(O)c1</smiles><smiles>O=c1cc(-c2ccc(O)c(O)c2)oc2cc(OC3O[C@H](CO)[C@@H](O)[C@H](O)[C@H]3O)cc(O)c12</smiles>

Luteolin-7-glucoside<smiles>O=c1cc(-c2ccc(O)cc2)oc2cc(OC3OC(CO)[C@@H](O)[C@H](O)[C@H]3O)cc(O)c12</smiles>

Apigenin-7-glucoside

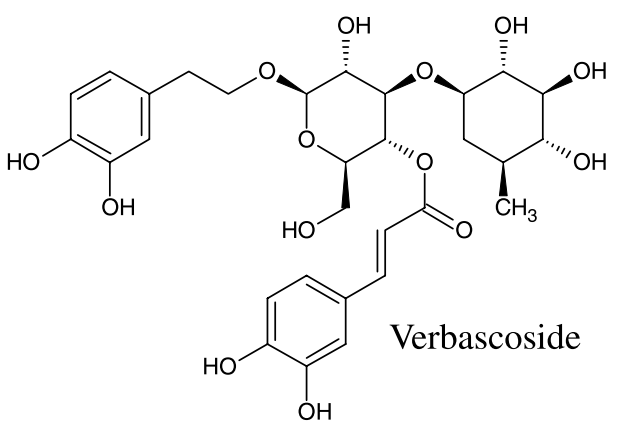

Hydroxytyrosol

Fig. 1. Most abundant phenolics present in olive leaf.

such as UV light. In addition, they also contribute significantly to the sensory properties of fruits and vegetables and products derived from them [7]. Following the consumption of polyphenol-rich foods, absorbed polyphenols have been postulated to exert a range of biological effects within the human body, via their potential to modulate the activity of a wide range of enzymes and cell receptors [8]. As such, it is perhaps unsurprising that diets rich in polyphenols have been found to decrease the incidence of chronic diseases [9].

Phenolic compounds consist of an aromatic ring with one or more hydroxyl groups. Over 8000 have been identified with structures ranging from simple monomeric units to complex oligomers and polymers [7]. With regards to the olive plant, a diverse range of phenolic compounds have been observed, although the most abundant and characteristic are the secoiridoid, oleuropein (the bitter compound found in olives), the simple phenols tyrosol and hydroxytyrosol (HT), the flavonoids luteolin and apigenin, and the phenolic acid verbascoside (Fig. 1). Secoiridoids are a group of coumarin-like compounds that are produced from the secondary metabolism of terpenes and are only present in plants of the Olearaceae family. Oleuropein is an ester of HT and elenolic acid glucoside, whilst verbascoside is a conjugated glucoside of HT and caffeic acid. 
Table 1

Concentration of most abundant phenolics present in olive leaves vs. olive oil. Olive oil data were derived from [11, 86, 140] and olive leaf [11, 57, 141-149]. n.d. denotes not detectable. Values derived from the following studies were converted to $\mathrm{mg} / \mathrm{kg}$ for comparison with other data $[144,145,148-150]$. Data sets resulting from the analysis of leaves and oils from different plant species, storage conditions and extraction methods were included to illustrate the variation in composition

\begin{tabular}{lcccccc}
\hline Range $(\mathrm{mg} / \mathrm{kg})$ & Hydroxtyrosol & Tyrosol & Luteolin-7-glucoside & Apigenin-7-glucoside & \multicolumn{1}{c}{ Verbascoside } & Oleuropein \\
\hline Olive oil & $0.5-14.4$ & $0.5-14.4$ & n.d. & n.d. & n.d.-0.1 & n.d.-2 \\
Olive leaf & n.d.-1160 & $14-89$ & $155-6000$ & $123-2333$ & $200-8500$ & $5526-26471$ \\
\hline
\end{tabular}

Table 2

Major (poly)phenolics extracted from olive leaves. Data derived from [15, 57, 141, 143, 151-156]

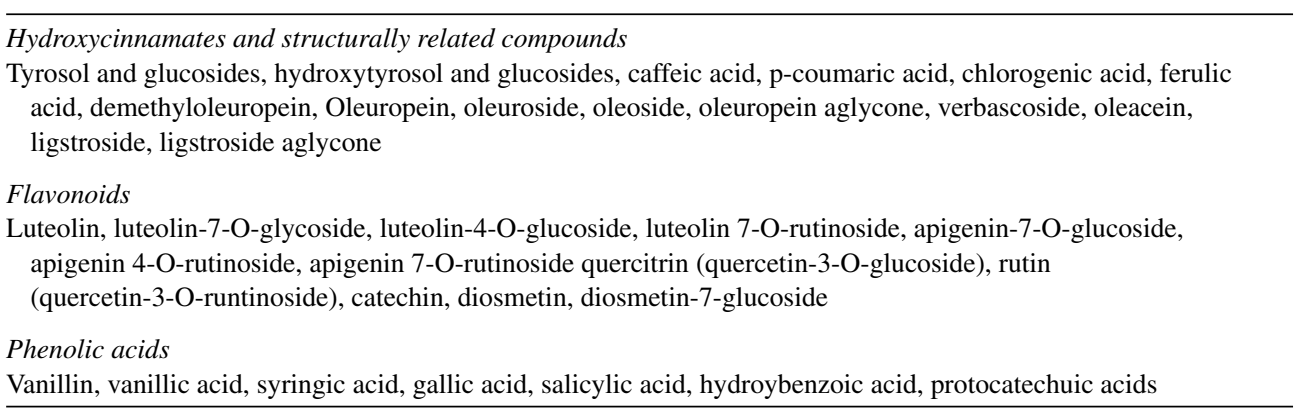

\section{Olive leaf (poly)phenolics}

Olive trees (Olea europaea) grow predominantly in Mediterranean countries, where extended periods of sunlight irradiation, as well as pathogen and insect attack, require plants to synthesise high levels of polyphenols for environmental defence [10]. These phenolic compounds are stored in thick leaves and dark fruits in order to prevent degradation. The leaves contain the highest overall concentration of phenolics within the plant, and the distribution of individual (poly)phenolic compounds varies between different plant structures (for a comparison between olive leaf and olive oil see Table 1). In particular, olive leaves are a significantly richer source of oleuropein compared to olive oil [11] and also contain higher amounts of glycosylated flavones. However, olive oil tends to be higher in flavone aglycones, as these develop in olives during ripening and thus are predominantly present in olive oil [12].

The phenolic composition of olive leaves varies according to plant variety, harvesting season, leaf maturity and storage conditions, and the detection of these phenolics is dependent on the extraction method, in terms of both the compounds identified and their quantities [13]. Phenolic compounds can be extracted from the leaves (after drying and milling) using various methods, including solid-liquid extraction by maceration and Soxhlet extraction using watermethanol mixes or hexane to give olive leaf extract (OLE) [14]. Numerous characterisation studies have reported a wide range of phenolic compounds to be present (Table 2). Oleuropein is present at levels of $1-14 \%$ in olive leaves $(\mathrm{w} / \mathrm{w})$ vs. $0.005-0.12 \%$ in olive oil [15], comprising up to $264 \mathrm{mg}$ per gram of dry leaf (when expressed as tyrosol equivalents) [14]. Other components present in olive leaf include $\beta$-carotene, squalene, tocopherols and alkaloids [14].

\section{Olive leaf and its uses}

Olive leaves are a waste product of olive oil production, which accumulate after the pruning and beating of olive trees for fruit removal [14]. Spain produces 6 million tonnes of olive leaves and small branches per year. This cheap raw material was previously burnt or used for animal feed. However, the health food industry has recently taken an interest in olive leaf and realised its potential as a source of beneficial olive phenolics [16]. The high in vitro antioxidant capacity of olive leaf extracts and related compounds have led to them being considered as ingredients in 'added value' pharmaceuticals, cosmetics and foods [10]. For example, oleuropein and HT are potent scavengers of superoxide and the hydroxyl radical in vitro [17], functionality 
which resides in the catechol moiety of their structures. Furthermore, an enhancement of this activity via synergism with other olive leaf phenolics has also been proposed [18]. This antioxidant nature of olive leaf extracts is being utilised along with antimicrobial properties for extending the shelf life of food products, particularly by the meat industry [19]. Furthermore, a range of olive leaf products are now available for human consumption, which are marketed for general health-promoting effects. The possibility of using phenolics extracted from olive leaves to enrich edible oils [20] and table olives [21] is also being explored. The composition of OLEs in these commercial products varies, but oleuropein is the principal component, normally contributing $20-40 \%$ to the total phenolics present.

\section{Bioavailability of olive oil/OLE phenolics}

Olive oil phenolics are absorbed to varying degrees throughout the gastrointestinal tract, with relatively rapid (1-2h) absorption occurring in the small intestine and late $(2-12 \mathrm{~h})$ bacterial-dependent absorption occurring in the large intestine. Furthermore, phenolics from olive oil are thought to have relatively high bioavailability compared with other polyphenols, such as flavonoids [22]. Although the absorption and metabolism of olive oil phenolics has been investigated [23-27], information regarding the bioavailability of those from OLE is lacking. Whilst olive oil studies are relevant and informative, the pharmacokinetics of phenolics present in OLE must be explored independently to gain realistic insight into their absorption and metabolism, as it has been demonstrated that the excretion of HT varies depending on the delivery vehicle, with bioavailability being higher when it is administered within olive oil compared to that of yoghurt [28] or aqueous solution [29]. Furthermore, OLE contains oleuropein glycoside, whereas olive oil contains predominantly oleuropein aglycone [30], and there is considerable uncertainty regarding the absorption of these forms in humans. Studies suggest that oleuropein aglycone is not present in human plasma or urine after olive oil consumption [12], whilst unmodified oleuropein (i.e. with the glucose moiety intact) has been detected in rat plasma/urine [24] and human urine [12] following the ingestion of oleuropein glycoside.

To date, only one human study has been performed to examine the urinary excretion of phenolics following OLE consumption [31]. Whilst this study did not examine the precise concentrations of phenolics or their metabolites in plasma, ingestion of OLE capsules (containing $60 \mathrm{mg}$ oleuropein) or a liquid extract (containing $66 \mathrm{mg}$ oleuropein) led to the detection of five oleuropein glucuronides in urine up to six hours after ingestion and after chronic supplementation [31]. Along with oleuropein glucuronides, oral administration of oleuropein glycoside in rodents also resulted in urinary excretion of the parent compound, HT and HT glucuronides [24], none of which were detected in the olive leaf bioavailability study. The lack of oleuropein degradation products measurable in urine following olive leaf ingestion suggests that oleuropein glycoside survives passage through the stomach intact, something which is supported by studies in ileostomy subjects [12]. In contrast, oleuropein aglycone appears to be partially hydrolysed by gastric juice to produce large amounts of free HT and tyrosol, which enter the small intestine [23], although this hydrolysis may be dependent on the post-prandial status of individuals [32].

\section{Small intestinal metabolism}

Following the consumption of extra virgin olive oil (EVOO), HT and tyrosol levels have been observed to increase in plasma and urine in a dose-dependent manner [33]. As is observed with other polyphenols, OLE phenolic compounds bearing a catechol group undergo $O$-methylation, sulphation and glucuronidation within enterocytes during transfer across the SI, with the proportion of the various conjugates generated varying according to the oral dose of phenolics and differences in availability of enzyme co-factors [34]. Both HT and tyrosol are $O$-glucuronidated [35] and HT is also $O$-methylated to homovanillic alcohol (HValc) via the action of the enzyme catechol-O-methyl-transferase (COMT) located within epithelial cells [36]. Ingestion of $25 \mathrm{~mL}$ olive oil (containing $1.2 \mathrm{mg} \mathrm{HT}$ ) was found to result in a peak plasma concentration of $25 \mathrm{ngmL}^{-1}$ of HT conjugates/metabolites, 30 minutes after intake

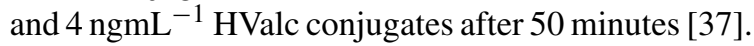

Oleuropein glycoside has been reported to be absorbed poorly [25], if at all [23]. Although these observations are based only on rat intestinal models, the polarity of the compound predicts that it would be unlikely to diffuse rapidly across lipid bilayers of epithelial cell membranes and it has been hypothesised that the small amount of oleuropein glycoside absorbed 
in these studies may be mediated by small intestinal, sodium-dependent glucose transporters [25]. In contrast, oleuropein aglycone may undergo a degree of small intestinal absorption due to its greater degree of lipophilicity and higher partition coefficient across membranes [38]. Indeed, results from Caco-2 monolayer experiments suggest that oleuropein aglycone and oleuropein aglycone di-aldehyde are both transferred [26], although it should be noted that these cells do not contain the full complement of intestinal enzymes (COMT and UDP-glucuronosyl transferase are largely absent) and as such do not wholly reflect physiological conditions in vivo. Perfused rat intestinal models indicate that during transfer across the ileum, and to a greater degree across the jejunum, oleuropein aglycone undergoes both a two-electron reduction and mono-glucuronidation at two positions [23]. These reactions are considered to be a consequence of the activity of aldose reductase present in enterocytes, which reduces the carbonyl group of oleuropein aglycone. Therefore, glucuronides of reduced oleuropein aglycone and oleuropein aglycone di-aldehyde may represent major metabolites entering the portal blood from the small intestine.

\section{Large intestinal metabolism}

Kendall and colleagues report that no metabolism of OLE phenolics occurs in the colon on the basis that they failed to detect microbiota-derived metabolites in urine 12-24 hours after ingestion of OLE capsules or liquid [31]. However, this is in contrast with a study which utilised faecal bacterial batch cultures to demonstrate that oleuropein was rapidly and extensively degraded to HT and two other, unidentified metabolites [23]. Individual variations in the gut microbiota did alter the time course of oleuropein metabolism, although the action on oleuropein was similar across all three human faecal donors. It is possible that the metabolites produced by the bacteria are not subsequently absorbed, something which requires further analysis, although such metabolites may still induce beneficial actions in the body by exerting local antioxidant activity in the GI tract [39].

\section{Tissue levels of olive phenolics}

In order to exert biological activity, it is important that absorbed compounds/metabolites reach the tissues and organs. HT administered intravenously to rats has been found to be rapidly and extensively taken up by organs and tissues, in particular renal tissues [40]. The 'depot hypothesis' states that conjugates of phenolics behave as carriers of free forms of the compounds to target tissues. Although this remains to be confirmed, if true, plasma or tissue levels may be more relevant than urinary levels [14].

\section{Potential health benefits of olive oil/OLE}

Olive related 'medicines' have been proposed as potential treatment for a variety of illnesses including hypertension, diabetes, urinary infections, headaches, liver colic, gastroenteritis, nephritis, wounds, burns and ulcers [41]. In 1854, the first report relating to the medicinal properties of an olive leaf extract towards fever and malaria was published [42]. More recently, a wide variety of potential health benefits have been reported for both OLE, and also individual components within OLE, including hypoglycaemic [43-46], immune-stimulant [47], anti-atherosclerotic [48], hypotensive [49], anti-oxidant [43], anti-tumour [50, 51], anti-HIV [52], radioprotective [53, 54], antimicrobial [55-58], neuroprotective [59, 60], antigout [61], analgesic [62] and anti-inflammatory [63] effects. Cardiovascular diseases (CVDs) are the biggest cause of death globally [64] and, as such, this review will only detail the effects of olive leaf phenolics on cardiovascular risk markers (for a summary of the current evidence, see Fig. 2). Modifiable risk factors for CVD include dyslipidaemia, hypertension, obesity and diabetes, all of which may be diet-induced [65]. Such factors are commonly assessed by measurement of blood pressure, endothelial dysfunction, arterial stiffness, plasma lipid profiles (an abnormal lipid profile is characterised by high total cholesterol (TC), low-density lipoprotein (LDL) cholesterol and triacylglyceride (TAG), and low high-density lipoprotein (HDL) cholesterol), inflammation (indicated by high circulating levels of various proteins, including CRP, ICAM-1, IL-6, IL-18), serological markers, such as fibrinogen and/or von Willebrand Factor, and markers of myocardial vulnerability, such as arrhythmia [66]. The following sections critically evaluate the in vivo evidence for the actions of olive leaf and OLE against CVD risk and pathology and examine the potential mechanisms of action of olive leaf polyphenols, the latter being based predominantly on in vitro work. 


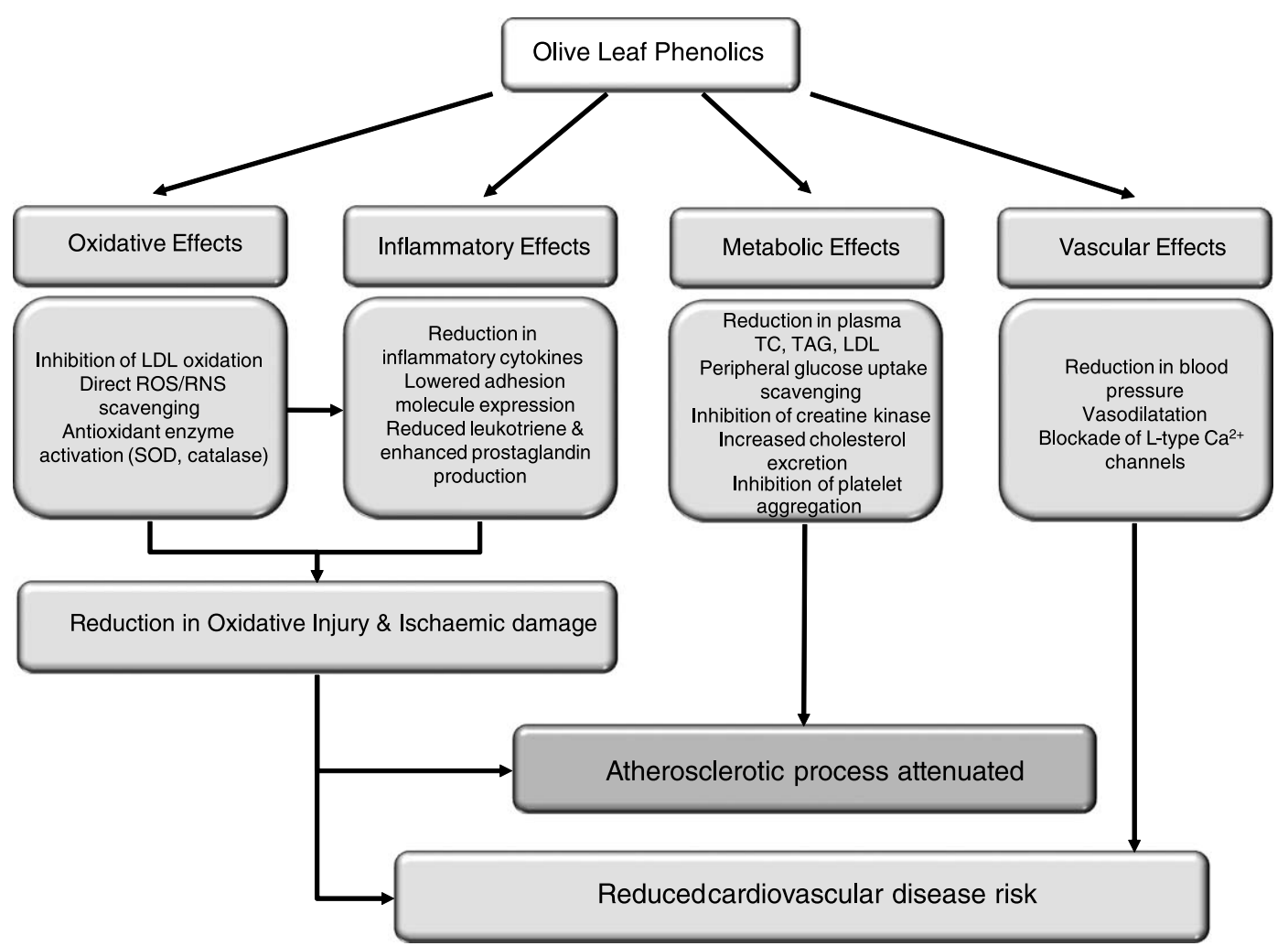

Fig. 2. Summary of the evidence in support of the affect of olive leaf phenolics on cardiovascular risk markers. TC $=$ total cholesterol, $\mathrm{TAG}=$ triacylglycerol, $\mathrm{LDL}=$ low-density lipoprotein cholesterol, $\mathrm{SOD}=$ super oxide dismutase, $\mathrm{ROS}=$ reactive oxygen species, $\mathrm{RNS}=$ reactive nitrogen species.

\section{Animal and ex vivo studies}

Early experiments with the OLE component, oleuropein, indicated that it possessed hypotensive, vasodilatory, anti-arrhythmic and spasmolytic actions in animals [67]. More recent animal studies have expanded upon these observations to detail the physiological effects and the potential biological mechanisms underlying activity. For example, OLE intervention has been shown to reduce blood pressure in both hypertensive [49, 68] and normotensive [69] rats. These observations are supported by ex vivo experiments in which OLE induces a concentration-dependent decrease in systolic left ventricular pressure and heart rate and an increase in relative coronary flow in isolated, perfused rabbit hearts [70]. Voltage clamp experiments using cultured rat cardiomyocytes indicate that these effects might be mediated by the blockade of L-type $\mathrm{Ca}^{2+}$ channels by specific OLE components, which is also proposed to underpin the vasoactive effects of HT on isolated aortic rings [71]. Oleuropein and OLE have also been observed to induce the relaxation of isolated rat aortas [72], whereas HT has been found to protect rat aortas from a cumene hydroperoxide-induced reduction in nitric-oxide (NO) mediated relaxation (a model of oxidative stressinduced vascular dysfunction) [73]. However, the latter studies using OLE or pure compounds are likely to be un-physiological in light of the reported absorption and metabolism data. As such, further experiments using individual olive leaf polyphenols and their metabolites at physiological concentrations will be necessary to confirm these direct actions on the vascular system.

Chronic supplementation with either OLE or an olive fruit extract has been shown to protect rats against diet-induced hypercholesterolaemia: improving the lipid profile, reducing the size of aortic lesions, limiting lipid peroxidation and enhancing antioxidant defence compared to control fed animals [59, 74, 75]. In agreement with this, olive 
oil enriched diets induce reductions in plasma TC, TAG and LDL and liver TC [76]. These actions have been positively correlated with the phenolic content of olive oil and may be mediated by the actions of olive components on bile flow, increasing biliary cholesterol and bile acid concentrations, leading to their increased faecal excretion. Another proposed mechanism with respect to their action on lipid metabolism is the ability to decrease cholesterol biosynthesis via the actions of absorbed OLE phenolics on key cholesterol-regulatory enzymes, 3-hydroxy3-methylglutaryl-CoA (HMG-CoA) reductase and acetyl-CoA cholesterol acyltransferase (ACAT) [77].

Hypoglycaemic effects of OLE have been repeatedly observed in animal models of diabetes [43-45, $68,78-80]$. It has been hypothesised that oleuropein and HT act as hypoglycemants via the enhancement of the peripheral uptake of glucose and increase the expression, or activity, of antioxidant enzymes [44, 79]. One study found OLE treatment to significantly reduce starch digestion and absorption [80]. Furthermore, OLE has been shown to prevent accumulation of abdominal fat, reverse ventricular stiffness, reduce collagen deposition, reduce inflammation and fibrosis of the liver and heart, reduce portal inflammation and fat deposition, and induce a restoration of liver function and aortic reactivity [81]. In diabetic rats, OLE supplementation has also been observed to restore superoxide dismutase (SOD) and catalase activities, increase antioxidant capacity, reduce lipid oxidation and other markers of oxidative stress and reverse hypercholesterolemia [43-45, 68].

With respect to changes in oxidative status, oleuropein $(20 \mathrm{mg} / \mathrm{kg}$ of tissue) has also been shown to protect against oxidative myocardial injury induced by ischaemia-reperfusion in isolated rat hearts [82]. The suggested mechanism involves the inhibition of cardiac creatine kinase release, glutathione oxidation and lipid peroxidation, although the data may be questioned because although the doses of oleuropein are comparable to dietary intakes achievable in the Mediterranean diet, the study does not take into account its absorption and metabolism, which would significantly influence the levels to which heart tissue would be exposed in vivo. Similar effects of OLE have been reported with respect to reducing the severity of cerebral ischemia/reperfusion brain injury, suggested to involve inhibition of superoxide and NO production, a decrease in lipid peroxidation and an increase in SOD activity [60]. A reduction in the levels of various oxidative damage biomarkers have been reported in an animal model of impaired endothelial function fed a phenolic-rich olive mill waste water (OMWW) [83], which may be mediated by the potential metal ion-chelating properties of oleuropein and other polyphenols [84], or by the exertion of inhibitory effects on inflammatory enzymes such as lipoxygenases [85]. With respect to inflammation, a HT-rich OLE has been reported to reduce the severity of atherosclerosis in rabbits and down regulate the expression of a variety of inflammatory mediators, including MCP-1, VCAM-1, NF- $\kappa \mathrm{B}$ and TNF- $\alpha$ at both the protein and mRNA level [48].

\section{Human studies}

OLE has been declared safe for human consumption, with the LD50 for hydroxytyrosol being above $5000 \mathrm{mg} / \mathrm{kg}$ [67]. Despite this, very few human studies have been performed to assess its potential health benefits. In contrast, numerous studies using olive oil have been conducted and indicate improvements in a variety of cardiovascular risk markers, (although because of design issues it has proved difficult to distinguish the contribution of the phenolics from the actions of MUFA); for a review see $[1,86]$. To address this, the effects of olive oils containing either high or low phenolic content have been utilised to provide more specific information regarding the actions of the phenolic components of the oil [87]. Nevertheless, while such studies give an indication of the bioactive role of olive leaf phenolics, the exact mixture and dose of phenolics found in olive oil is very different from that found in olive leaves; thus, separate human studies are required to fully assess OLE activity.

The anti-hypertensive and cholesterol-lowering actions of OLE have been repeatedly observed in animal studies [49, 88, 89]. Consistent with these results, the OLE preparation EFLA®943 (containing 19.9\% oleuropein) has been observed to reduce systolic and diastolic blood pressure and to lower cholesterol in a clinical study carried out in 20 monozygotic adult twin pairs with mild hypertension [90]. Subsequent to this, the efficacy of the same preparation versus a standard stage- 1 hypertension drug was indicated in a double blind, randomised, parallel study carried out in 148 patients [91]. The subjects consumed either $500 \mathrm{mg}$ EFLA®943 twice per day (equivalent to $199 \mathrm{mg}$ oleuropein) or $12.5-25 \mathrm{mg}$ Captopril, with 
the former effective in reducing systolic and diastolic blood pressure to the same degree as Captopril, but also in improving the lipid profile. Whilst these studies present promising evidence for an antihypertensive property of OLE, additional studies using 24 hour ambulatory blood pressure, which is known to provide greater accuracy [92] would be more appropriate. The mechanisms underlying these antihypertensive effects may involve the inhibition of angiotensin converting enzyme (ACE) by oleacein (observed in vitro [93]) and/or calcium-antagonistic activities of oleuropein (observed in animal and ex vivo studies [70, 71]), although such activity is yet to be fully characterised in human studies.

The protective effects of chronic OLE supplementation against CVD risk have also been highlighted in further chronic supplementation studies, where $1.2 \mathrm{~g}$ of OLE was ingested per day for 28 days, leading to significant improvements in cholesterol status (reduced total cholesterol, decreased LDL cholesterol etc.) in hypercholesterolemic subjects [94] and $1.6 \mathrm{~g}$ of OLE per day for three months leading to a significant decrease in blood pressure in hypertensive patients [95]. Additional effects of olive leaf supplementation ( $1 \mathrm{~g}$ ) (along with $300 \mathrm{~g}$ white rice) have been observed in borderline diabetics, where intake led to a significant reduction in blood glucose at 30 and 60 minutes post supplementation [78], perhaps mediated by the inhibitory action of OLE polyphenols on intestinal and/or salivary $\alpha$-amylases. A large recent study found that 14 weeks of $500 \mathrm{mg}$ OLE supplementation significantly lowered HbAlc (glycosylated haemoglobin) and fasting plasma insulin levels in 79 type 2 diabetics [80]. No significant changes in urinary $\mathrm{F}_{2 \alpha}$-isoprostanes (8-iso-PGF $2 \alpha$ ), a marker of lipid peroxidation; $8-\mathrm{OHdG}$, a measure of DNA oxidation; or total reducing capacity were observed following the intake of OLE supplementation in healthy adults [96], although it was noted that oxidative stress may not be significant in a young healthy cohort. Previous data regarding the impact of olive phenolics on markers of oxidative stress are conflicting with some noting reductions in DNA oxidation (presumed to be due to MUFA rather than polyphenols as the reduction from refined oil was identical to medium and high phenolic oils) [97] and a reduction in the urinary excretion of 8 -iso- $\mathrm{PGF}_{2 \alpha}$ (correlated with urinary HValc levels) [98], and others indicating that HT-rich OMWW extract has no acute effect on urinary 8 -iso- $\mathrm{PGF}_{2 \alpha}$. These differing results could be attributed to the use of very different olive interventions. In addition studies may be underpowered as a consequence of the OLE phenolic bioavailability being greatly affected by genetic factors (e.g. COMT genotype) or differences in composition of gut microbiota [99].

A small number of human studies have reported the effect of chronic olive oil consumption (as part of a prescribed Mediterranean diet) on vascular function, with improvements reported in diabetic [100] and hypercholesterolaemic [101] patients and those with the metabolic syndrome [102]. However, this evidence is difficult to interpret, as it is difficult to delineate the contribution of olive phenolics, MUFAs or other components within olive oil. More focussed studies using high and low phenolic olive oils have highlighted the beneficial effects of olive phenolics on endothelial-dependent vascular function through actions on NO bioavailability [103]. These effects also interact with the Glu298Asp eNOS polymorphism, such that endothelial dysfunction associated with the TT genotype was ameliorated after acute consumption of olive oil [104]. It has also been demonstrated that 3 month use of olive oil is associated with reduced susceptibility of LDL to oxidation and reduced uptake by macrophages [87]. These effects may be mediated by the incorporation of olive phenolics, such as tyrosol, HT, HT glucuronide, HT sulphate, tyrosol glucuronide, tyrosol sulphate and homovanillic acid sulphate into LDL particles [105, 106], indicating that phenolic metabolites derived from olive could prevent $\mathrm{LDL}$ oxidation, a known key contributor to the process of atherosclerosis [107]. Consistent with this suggestion, OLE has been demonstrated to inhibit LDL oxidation in vitro [108], although the in vitro conditions are unlikely to be physiological and this remains to be confirmed in vivo.

\section{Potential mechanisms of action}

Many of the initial investigations into the beneficial properties of olive phenolics centred on research into their potential to reduce oxidative stress [109]. Oxidative stress is well known to damage lipid membranes, proteins, and DNA [110] and has been linked to the development of many diseases, including CVD [110]. Historically, dietary-derived polyphenols were thought to act as antioxidants in vivo by direct scavenging of oxidants. However, it now seems more likely that polyphenols, including those found in olive 
oil and olive leaf, exert biological function through interactions with membrane receptors and/or enzymes involved in cell signalling, resulting in an indirect modification of the redox status of cells [111]. Polyphenols have been noted to affect a variety of biomarkers of oxidative stress status [112], although the relevance of many of these to the disease is questionable [113]. The antioxidant potential of OLE has been observed in vitro [58], with HT proposed to scavenge predominantly peroxyl radicals near membrane surfaces and oleuropein also acting on chain-propagating lipid peroxyl radicals within cell membranes [114]. Flavonoids are thought to account for $13-27 \%$ of the radical-scavenging activity of OLE with luteolin 7-Oglucoside one of the most dominant scavengers [115]. However, whilst several studies have cited antioxidant capacity as being the main mode of action of olive polyphenols in vivo, it is now thought highly unlikely that this is the major or sole mechanism for their actions in the body.

An alternative or additional potential mechanism of action is modulation of inflammation [116]. Monocyte adhesion to endothelial cells, a critical stage in early atherosclerosis, is mediated by the increased expression of endothelial leukocyte adhesion molecules such as VCAM-1, ICAM-1 and E-selectin. Studies have indicated that oleuropein aglycone, HT, tyrosol and HValc are capable of inhibiting the expression of such factors on the surface of endothelial cells in vitro [117-119]. Such modulatory effects may be mediated at the mRNA level [118], through blocking activator protein- 1 and NF- $\kappa$ B activation [117], or by quenching oxidants, which themselves induce surface expression of adhesion molecules [118]. Such effects have been noted at physiological concentrations below $1 \mu \mathrm{M}$, although at present have not taken into account the potential effects of metabolites.

Increased platelet aggregation is also associated with enhanced atherogenicity [120]. Phenolic-rich OMWW extract has been reported to inhibit platelet aggregation in vitro, by a mechanism involving inhibition of the eicosanoid pathway [63]. Furthermore, HT potently inhibited the production of leukotriene-B4 by stimulated human polymorphonuclear leukocytes in vitro [121]. Individual olive leaf phenolics have been demonstrated to exert selective inhibitory activity against leukotriene-B4 production by rat leukocytes whilst sparing the cyclooxygenase pathway of prostaglandin production, which is necessary for promoting microvascular flow and modulating the immune system [85]. The order of effectiveness was observed as HT > oleuropein > caffeic acid > tyrosol, seemingly in line with antioxidant capacity and their ability to inhibit the generation of oxidants during respiratory burst and superoxide generation by hypoxanthine/xanthine oxidase. Similarly, stimulated adherent macrophages produce less superoxide in the presence of OMWW extract and after pre-treatment [122]. In the majority of the aforementioned studies, it has been postulated that HT is likely to be the most active component due to its high antioxidant potential [83]. These findings are supported by a small human study in which five type I diabetics were fed four consecutive daily doses of HT and experienced a clinically significant reduction in plasma thromboxane-B2, an arachidonic acid metabolite which is indicative of the aggregating potential of platelets [123]. Oleuropein glycoside and caffeic acid have also been found to decrease substantially IL-1 $\beta$ production in human whole blood cultures stimulated with LPS [124], although no modulation of TNF- $\alpha$ or IL-6 production was observed. A new class of orthodiphenols present in olive oil was also reported to suppress thromboxane $\mathrm{A}_{2}, \mathrm{PGE}_{2}$ and $\mathrm{TNF}-\alpha$ production by LPS-stimulated PBMCs [125]. However these compounds are formed via a reaction between HT and aldehydes and ketones during the malaxation process of olive oil production and are therefore unlikely to be present in OLE.

Another proposed mechanism of action of olive leaf phenolics relating particularly to blood pressure and platelet function is modulation of NO bioavailability. As previously mentioned, consumption of phenolicrich olive oil has been demonstrated to increase NO bioavailability, thus improving vascular function in humans [103, 104]. However, since excess production has been implicated in inflammation and cancer, homeostatic regulation of NO production is critical [126]. Oleuropein and HT have been shown to react directly with $\mathrm{NO}$ and its toxic derivative peroxynitrite (-OONO) [27], an action also ascribed to tyrosol [127]. Furthermore, oleuropein increases the expression of the inducible form of NO synthase (iNOS) in mouse macrophages [47]. In addition to acting on the NO system, olive polyphenols may act on nicotinamide adenine dinucleotide phosphate (NADPH) oxidases, which generate superoxide in the vasculature [128] and have been implicated to play a role in vascular diseases [129-131] and linked with the severity of atherosclerosis [132] and hypertension [133]. 
For example, resveratrol [134, 135], curcumin [136], phenolic-rich red wine [137], green and black tea extracts [138], $3^{\prime}$-and $4^{\prime}-O$-methyl epicatechin, procyanidin B2 and (-)-epicatechin glucuronide [139] have all been observed to inhibit Nox activity and/or its expression.

It should be emphasised that the data emerging from many of the in vitro and ex vivo studies should be interpreted with caution. In particular, for ex vivo studies to accurately reflect in vivo conditions, phenolics and their metabolites must be applied to tissues at realistic, physiological concentrations. At present, the closest estimate of tissue levels is thought to be peak plasma concentrations following oral administration, likely to be in the region of low nano-molar to low micro-molar levels. One limiting factor is that the absorption and metabolism of phenolics following the ingestion of OLE is relatively unknown. As detailed above, the exposure of tissues to phenolics found within olive leaf and/or whole olive leaf extracts is un-physiological. In addition, the intake of OLE will result in a number of phenolics and metabolites reaching the tissues at various concentrations. Thus, the activity of single phenolic compounds in cell and ex vivo studies provides only limited information on the full biological potential of OLE efficacy in vivo, and potential synergistic effects may be overlooked. Thus, further ex vivo work is required to confirm whether some of the reported effects above are physiologically relevant. The same degree of caution should also be applied to the interpretation of animal studies, primarily due to the potential differences in absorption and metabolic activity between animals and humans. As such, there is a clear need for well-designed, controlled human studies.

\section{Future perspectives}

As previously mentioned, there is a distinct lack of good quality human data regarding the biological effects of olive leaf consumption, including the establishment of bioavailability. To date, only the urinary metabolites of OLE have been measured after its consumption. It is essential that future studies examine plasma, urine and faeces for the presence of phenolics in order to fully elucidate the bioavailability OLE (poly)phenols and provide information regarding the potential bioactive metabolites. Furthermore, how the absorption and metabolism of OLE phenolics is influenced by OLE dose, the delivery matrix (e.g. liquid, capsules, foods), nutrient-nutrient interactions/postprandial status and various individual differences, such as genotype, age and gender would allow for a more accurate assessment of the physiological effects of OLE in humans.

As this review has illustrated, OLE can have a relatively widespread effect on cardiovascular risk markers, including on blood pressure, glycaemic status, lipid profile and inflammatory oxidative status. However, there are still a relatively small number of human studies indicating hypoglycaemic, lipid and blood pressure lowering effects. Furthermore, the mechanisms by which OLE induces such effects remain to be elucidated. Measurement of circulating nitric oxide metabolites (NOx, such as nitrate, nitrite and nitrosothiols) may provide an insight into whether absorbed OLE phenolics enhance nitric oxide bioavailability, perhaps through an enhancement of NO production or via an inhibition of endothelial NADPH oxidase. Further mechanistic insights into the effects of OLE on vascular function may come through the measurement of inflammatory mediators, such as cytokines and CRP, markers of platelet aggregation and LDL oxidation. With respect to in vitro or ex vivo studies of mechanism, future studies must use compounds and/or metabolites in physiologically relevant concentrations and in the correct proportions that would reach tissues in vivo.

Considering that humans are in the postprandial state for most of the day, the influence of OLE on physiology under postprandial conditions seems very relevant. Such data would reveal the impact of OLE on 'real life' postprandial markers of inflammatory cytokine release, glucose and lipid profiles and arterial stiffness, following a typical high fat and/or carbohydrate meal. Of course, further chronic supplementation studies are also necessary, especially in relation to blood pressure, and such studies will generate valuable data regarding the potential of OLE to benefit individuals suffering from chronic inflammation such as obese patients, an increasingly significant problem in the current health climate.

\section{Acknowledgments}

SL is grateful for financial support from Comvita. Comvita has received research and development funding from the Ministry of Science and Innovation, New Zealand. 


\section{References}

[1] López-Miranda J, Pérez-Jiménez F, Ros E, De Caterina R, Badimón L, Covas MI, et al. Olive oil and health: Summary of the II international conference on olive oil and health consensus report, Jaén and Córdoba (Spain) 2008. Nutrition, Metabolism and Cardiovascular Diseases. 2010;20(4): 284-94.

[2] Carlo LV. An overview of Italian studies of Mediterranean diet and cancer. Toxicology Letters. 2006;164(Suppl 0):S6.

[3] Cicerale S, Lucas L, Keast R. Biological activities of phenolic compounds present in virgin olive oil. International Journal of Molecular Sciences. 2010;11(2):458-79.

[4] Aguilera CM, Mesa MD, Ramirez-Tortosa MC, Nestares MT, Ros E, Gil A. Sunflower oil does not protect against LDL oxidation as virgin olive oil does in patients with peripheral vascular disease. Clinical nutrition (Edinburgh, Scotland). 2004;23(4):673-81.

[5] Harper CR, Edwards MC, Jacobson TA. Flaxseed oil supplementation does not affect plasma lipoprotein concentration or particle size in human subjects. The Journal of Nutrition. 2006;136(11):2844-8.

[6] Yang D-P, Kong D-X, Zhang H-Y. Multiple pharmacological effects of olive oil phenols. Food Chemistry. 2007;104(3):1269-71.

[7] Ignat I, Volf I, Popa VI. A critical review of methods for characterisation of polyphenolic compounds in fruits and vegetables. Food Chemistry. 2011;126(4):1821-35.

[8] Middleton E, Kandaswami C, Theoharides TC. The effects of plant flavonoids on mammalian cells: Implications for inflammation, heart disease, and cancer. Pharmacological Reviews. 2000;52(4):673-751.

[9] Visioli F, Lastra CADL, Andres-Lacueva C, Aviram M, Calhau C, Cassano A, et al. Polyphenols and human health: A prospectus. Critical Reviews in Food Science and Nutrition. 2011;51(6):524-46

[10] Erbay Z, Icier F. The importance and potential uses of olive leaves. Food Reviews International. 2010;26(4):319-34.

[11] Luján RJ, Capote FP, Marinas A, de Castro MDL. Liquid chromatography/triple quadrupole tandem mass spectrometry with multiple reaction monitoring for optimal selection of transitions to evaluate nutraceuticals from olive-tree materials. Rapid Communications in Mass Spectrometry. 2008;22(6):855-64.

[12] Vissers MN, Zock PL, Roodenburg AJC, Leenen R, Katan MB. Olive oil phenols are absorbed in humans. The Journal of Nutrition. 2002;132(3):409-17.

[13] Ranalli A, Contento S, Lucera L, Di Febo M, Marchegiani D, Di Fonzo V. Factors affecting the contents of iridoid oleuropein in olive leaves (Olea europaea L.). Journal of Agricultural and Food Chemistry. 2005;54(2):434-40.

[14] Preedy VRaW, Ronald Ross. Olives and Olive Oil in Health and Disease Prevention: Elsevier Inc; 2010.

[15] Luque de Castro MD, Japón-Luján R. State-of-the-art and trends in the analysis of oleuropein and derivatives. TrAC Trends in Analytical Chemistry. 2006;25(5):501-10.

[16] Tabera J, Guinda Á, Ruiz-Rodríguez A, Señoráns FJ, Ibáñez E, Albi T, et al. Countercurrent supercritical fluid extraction and fractionation of high-added-value compounds from a hexane extract of olive leaves. Journal of Agricultural and Food Chemistry. 2004;52(15):4774-9.

[17] Capasso R, Evidente A, Avolio S, Solla F. A Highly convenient synthesis of hydroxytyrosol and its recovery from agricultural waste waters. Journal of Agricultural and Food Chemistry. 1999;47(4):1745-8.

[18] Keys A. Mediterranean diet and public health: Personal reflections. The American Journal of Clinical Nutrition. 1995;61(6): 1321S-3S

[19] Hayes JE, Stepanyan V, Allen P, O'Grady MN, Kerry JP. Effect of lutein, sesamol, ellagic acid and olive leaf extract on the quality and shelf-life stability of packaged raw minced beef patties. Meat Science. 2010;84(4):613-20.

[20] Japón-Luján R, Janeiro P, Luque de Castro MaD. Solid-liquid transfer of biophenols from olive leaves for the enrichment of edible oils by a dynamic ultrasound-assisted approach. Journal of Agricultural and Food Chemistry. 2008;56(16):7231-5.

[21] Lalas S, Athanasiadis V, Gortzi O, Bounitsi M, Giovanoudis I, Tsaknis J, et al. Enrichment of table olives with polyphenols extracted from olive leaves. Food Chemistry. 2011;127(4):1521-5.

[22] Visioli F, Galli C, Bornet F, Mattei A, Patelli R, Galli G, et al. Olive oil phenolics are dose-dependently absorbed in humans. FEBS Letters. 2000;468(2-3):159-60.

[23] Corona G, Tzounis X, Assunta Dessì M, Deiana M, Debnam ES, Visioli F, et al. The fate of olive oil polyphenols in the gastrointestinal tract: Implications of gastric and colonic microflora-dependent biotransformation. Free Radical Research. 2006;40(6):647-58.

[24] Del Boccio P, Di Deo A, De Curtis A, Celli N, Iacoviello L, Rotilio D. Liquid chromatography-tandem mass spectrometry analysis of oleuropein and its metabolite hydroxytyrosol in rat plasma and urine after oral administration. Journal of Chromatography B. 2003;785(1):47-56.

[25] Edgecombe SC, Stretch GL, Hayball PJ. Oleuropein, an antioxidant polyphenol from olive oil, is poorly absorbed from isolated perfused rat intestine. The Journal of Nutrition. 2000;130(12):2996-3002.

[26] Pinto J, Paiva-Martins F, Corona G, Debnam ES, OrunaConcha MJ, Vauzour D, et al. Absorption and metabolism of olive oil secoiridoids in the small intestine. Anglais. 2011;105(11):12.

[27] Tuck KL, Hayball PJ. Major phenolic compounds in olive oil: Metabolism and health effects. The Journal of Nutritional Biochemistry. 2002;13(11):636-44.

[28] Visioli F, Galli C, Grande S, Colonnelli K, Patelli C, Galli $\mathrm{G}$, et al. Hydroxytyrosol excretion differs between rats and humans and depends on the vehicle of administration. The Journal of Nutrition. 2003;133(8):2612-5.

[29] Tuck KL, Freeman MP, Hayball PJ, Stretch GL, Stupans I. The In Vivo fate of hydroxytyrosol and tyrosol, antioxidant phenolic constituents of olive oil, after intravenous and oral dosing of labeled compounds to rats. The Journal of Nutrition. 2001;131(7):1993-6.

[30] Visioli F, Galli C. Biological properties of olive oil phytochemicals. Critical Reviews in Food Science and Nutrition. 2002;42(3):209-21.

[31] Kendall M, Batterham M, Callahan DL, Jardine D, Prenzler PD, Robards K, et al. Randomized controlled study 
of the urinary excretion of biophenols following acute and chronic intake of olive leaf supplements. Food Chemistry. 2012;130(3):651-9.

[32] Markopoulos C, Vertzoni M, Agalias A, Magiatis P, Reppas C. Stability of oleuropein in the human proximal gut. Journal of Pharmacy and Pharmacology. 2009;61(2):143-9.

[33] Miro-Casas E, Covas MI, Fito M, Farre-Albadalejo M, Marrugat $\mathrm{J}$, de la Torre $\mathrm{R}$. Tyrosol and hydroxytyrosol are absorbed from moderate and sustained doses of virgin olive oil in humans. Eur J Clin Nutr. 2003;57(1):186-90.

[34] Del Rio D, Costa LG, Lean MEJ, Crozier A. Polyphenols and health: What compounds are involved? Nutrition, Metabolism and Cardiovascular Diseases. 2010;20(1):1-6.

[35] Miró-Casas E, Farré Albaladejo M, Covas M-I, Rodriguez JO, Menoyo Colomer E, Lamuela Raventós RM, et al. Capillary gas chromatography-mass spectrometry quantitative determination of hydroxytyrosol and tyrosol in human urine after olive oil intake. Analytical Biochemistry. 2001;294(1):63-72.

[36] Manna C, Galletti P, Maisto G, Cucciolla V, D’Angelo S, Zappia V. Transport mechanism and metabolism of olive oil hydroxytyrosol in Caco-2 cells. FEBS Letters. 2000;470(3):341-4.

[37] Miro-Casas E, Covas M-I, Farre M, Fito M, Ortuño J, Weinbrenner $\mathrm{T}$, et al. Hydroxytyrosol disposition in humans. Clinical Chemistry. 2003;49(6):945-52.

[38] Paiva-Martins F, Gordon MH, Gameiro P. Activity and location of olive oil phenolic antioxidants in liposomes. Chemistry and Physics of Lipids. 2003;124(1):23-36.

[39] Ursini F, Zamburlini A, Cazzolato G, Maiorino M, Bon GB, Sevanian A. Postprandial plasma lipid hydroperoxides: A possible link between diet and atherosclerosis. Free Radical Biology and Medicine. 1998;25(2):250-2.

[40] D’Angelo S, Manna C, Migliardi V, Mazzoni O, Morrica P, Capasso G, et al. Pharmacokinetics and metabolism of hydroxytyrosol, a natural antioxidant from olive oil. Drug Metabolism and Disposition. 2001;29(11):1492-8.

[41] Leporatti ML, Posocco E, Pavesi A. Some new therapeutic uses of several medicinal plants in the province of Terni (Umbria, Central Italy). Journal of Ethnopharmacology. 1985;14(1):65-8.

[42] Hanbury D. On the febrifuge properties of the olive (Olea europea, L.). Pharmaceutical Journal of Provincial Transactions. 1854:353-4.

[43] Al-Azzawie HF, Alhamdani M-SS. Hypoglycemic and antioxidant effect of oleuropein in alloxan-diabetic rabbits. Life Sciences. 2006;78(12):1371-7.

[44] Jemai H, El Feki A, Sayadi S. Antidiabetic and antioxidant effects of hydroxytyrosol and oleuropein from olive leaves in alloxan-diabetic rats. Journal of Agricultural and Food Chemistry. 2009;57(19):8798-804.

[45] Eidi A, Eidi M, Darzi R. Antidiabetic effect of Olea europaea L. In normal and diabetic rats. Phytotherapy Research. 2009;23(3):47-50.

[46] Sato H, Genet C, Strehle A, Thomas C, Lobstein A, Wagner A, et al. Anti-hyperglycemic activity of a TGR5 agonist isolated from Olea europaea. Biochemical and Biophysical Research Communications. 2007;362(4):793-8.
[47] Visioli F, Bellosta S, Galli C. Oleuropein, the bitter principle of olives, enhances nitric oxide production by mouse macrophages. Life Sciences. 1998;62(6):541-6.

[48] Wang L, Geng C, Jiang L, Gong D, Liu D, Yoshimura H, et al. The anti-atherosclerotic effect of olive leaf extract is related to suppressed inflammatory response in rabbits with experimental atherosclerosis. European Journal of Nutrition. 2008;47(5):235-43.

[49] Khayyal MT, Elghazaly MA, Abdallah DM, Nassar NN, Okpanyi SN, M-H K. Blood pressure lowering effect of an olive leaf extract (Olea europaea) in L-NAME induced hypertension in rats. Arzneimittel-Forschung (Drug Research). 2002;52(11):797-802.

[50] Hamdi HK, Castellon R. Oleuropein, a non-toxic olive iridoid, is an anti-tumor agent and cytoskeleton disruptor. Biochemical and Biophysical Research Communications. 2005;334(3):769-78.

[51] Anter J, Fernández-Bedmar Z, Villatoro-Pulido M, DemydaPeyras S, Moreno-Millán M, Alonso-Moraga Á, et al. A pilot study on the DNA-protective, cytotoxic, and apoptosis-inducing properties of olive-leaf extracts. Mutation Research/Genetic Toxicology and Environmental Mutagenesis. 2011;723(2):165-70.

[52] Lee-Huang S, Zhang L, Lin Huang P, Chang Y-T, Huang PL. Anti-HIV activity of olive leaf extract (OLE) and modulation of host cell gene expression by HIV-1 infection and OLE treatment. Biochemical and Biophysical Research Communications. 2003;307(4):1029-37.

[53] Budiyanto A, Ahmed NU, Wu A, Bito T, Nikaido O, Osawa T, et al. Protective effect of topically applied olive oil against photocarcinogenesis following UVB exposure of mice. Carcinogenesis. 2000;21(11):2085-90.

[54] Benavente-Garcia O, Castillo J, Lorente J, Alcaraz M. Radioprotective effects in vivo of phenolics extracted from Olea europaea L. leaves against X-ray-induced chromosomal damage: Comparative study versus several flavonoids and sulfur-containing compounds. Journal of Medicinal Food. 2002;5(3):125-35.

[55] Fredrickson W, Inventor Method and Composition for Antiviral Therapy 2002.

[56] Sudjana AN, D’Orazio C, Ryan V, Rasool N, Ng J, Islam $\mathrm{N}$, et al. Antimicrobial activity of commercial Olea europaea (olive) leaf extract. International Journal of Antimicrobial Agents. 2009;33(5):461-3.

[57] Pereira A, Ferreira I, Marcelino F, Valentão P, Andrade $\mathrm{P}$, Seabra R, et al. Phenolic compounds and antimicrobial activity of olive (Olea europaea L. Cv. Cobrançosa) Leaves. Molecules. 2007;12(5):1153-62.

[58] Lee O-H, Lee B-Y. Antioxidant and antimicrobial activities of individual and combined phenolics in Olea europaea leaf extract. Bioresource Technology. 2010;101(10):3751-4.

[59] Mohagheghi F, Bigdeli MR, Rasoulian B, Hashemi P, Pour MR. The neuroprotective effect of olive leaf extract is related to improved blood-brain barrier permeability and brain edema in rat with experimental focal cerebral ischemia. Phytomedicine. 2011;18(2-3):170-5.

[60] Dekanski D, Selaković V, Piperski V, Radulović Ž, Korenić A, Radenović L. Protective effect of olive leaf extract on 
hippocampal injury induced by transient global cerebral ischemia and reperfusion in Mongolian gerbils. Phytomedicine. 2011;18(13):1137-43.

[61] Flemmig J, Kuchta K, Arnhold J, Rauwald HW. Olea europaea leaf (Ph. Eur.) extract as well as several of its isolated phenolics inhibit the gout-related enzyme xanthine oxidase. Phytomedicine. 2011;18(7):561-6.

[62] Esmaeili-Mahani S, Rezaeezadeh-Roukerd M, Esmaeilpour K, Abbasnejad M, Rasoulian B, Sheibani V, et al. Olive (Olea europaea L.) leaf extract elicits antinociceptive activity, potentiates morphine analgesia and suppresses morphine hyperalgesia in rats. Journal of Ethnopharmacology. 2010;132(1):200-5.

[63] Petroni A, Blasevich M, Salami M, Papini N, Montedoro $\mathrm{GF}$, Galli C. Inhibition of platelet aggregation and eicosanoid production by phenolic components of olive oil. Thrombosis Research. 1995;78(2):151-60.

[64] World Health Organisation. http://www.who.int/ mediacentre/ factsheets/fs317/en/index.html. [cited].

[65] Deaton C, Froelicher ES, Wu LH, Ho C, Shishani K, Jaarsma T. The global burden of cardiovascular disease. Journal of Cardiovascular Nursing. 2011;26(4):S5-14.

[66] Vasan RS. Biomarkers of Cardiovascular Disease. Circulation. 2006;113(19):2335-62.

[67] Petkov V, Manolov P. Pharmacological analysis of the iridoid oleuropein. Arzneimittel-Forschung (Drug Research). 1972;22:1476-88.

[68] Somova LI, Shode FO, Ramnanan P, Nadar A. Antihypertensive, antiatherosclerotic and antioxidant activity of triterpenoids isolated from Olea europaea, subspecies africana leaves. Journal of Ethnopharmacology. 2003;84(23):299-305.

[69] Lasserre B, Kaiser R, Huu Chanh P, Ifansyah N, Gleye J, Moulis C. Effects on rats of aqueous extracts of plants used in folk medicine as antihypertensive agents. Naturwissenschaften. 1983;70(2):95-6.

[70] Scheffler A, Rauwald HW, Kampa B, Mann U, Mohr FW, Dhein S. Olea europaea leaf extract exerts L-type $\mathrm{Ca} 2+$ channel antagonistic effects. Journal of Ethnopharmacology. 2008;120(2):233-40.

[71] Rauwald HW, Brehm O, Odenthal KP. Screening of nine vasoactive medicinal plants for their possible calcium antagonistic activity. Strategy of selection and isolation for the active principles of Olea europaea and Peucedanum ostruthium. Phytotherapy Research. 1994;8(3):135-40.

[72] Zarzuelo A, Duarte J, Jiménez J, González M, Utrilla MP. Vasodilator effect of olive leaf. Planta Med. 1991;57(5):4179.

[73] Rietjens S, Bast A, Haenen G. The olive oil antioxidant hydroxytyrosol protects the aorta against oxidative stress. Chemico-Biological Interactions. 2007;169(2): 140.

[74] Jemai H, Bouaziz M, Fki I, El Feki A, Sayadi S. Hypolipidimic and antioxidant activities of oleuropein and its hydrolysis derivative-rich extracts from chemlali olive leaves. Chemico-Biological Interactions. 2008;176(2-3): 88-98.

[75] Fki I, Bouaziz M, Sahnoun Z, Sayadi S. Hypocholesterolemic effects of phenolic-rich extracts of chemlali olive cultivar in rats fed a cholesterol-rich diet. Bioorganic \& Medicinal Chemistry. 2005;13(18):5362-70.

[76] Krzeminski R, Gorinstein S, Leontowicz H, Leontowicz M, Gralak M, Czerwinski J, et al. Effect of different olive oils on bile excretion in rats fed cholesterol-containing and cholesterol-free diets. Journal of Agricultural and Food Chemistry. 2003;51(19):5774-9.

[77] Lee J-S, Choi M-S, Jeon S-M, Jeong T-S, Park YB, Lee $\mathrm{M}-\mathrm{K}$, et al. Lipid-lowering and antioxidative activities of 3,4-di $(\mathrm{OH})$-cinnamate and 3,4-di $(\mathrm{OH})$-hydrocinnamate in cholesterol-fed rats. Clinica Chimica Acta. 2001;314(12):221-9.

[78] Komaki EYS, Maru I, Kinoshita M, Kakehi K, Ohta Y, Tsukada Y. Identification of anti- $\alpha$-amylase components from olive leaf extracts. FSTR. 2003;9:35-9.

[79] Gonzalez M, Zarzuelo A, Gamez MJ, Utrilla MP, Jimenez J, Osuna I. Hypoglycemic activity of olive leaf. Planta Med. 1992;58(6):513-5.

[80] Wainstein J, Ganz T, Boaz M, Dayan YB, Dolev E, Kerem Z, Madar Z. Olive leaf extract as a hypoglycemic agent in both human diabetic subjects and in rats. Journal of Medicinal Food. 2012;15(7):605-10.

[81] Poudyal H, Campbell F, Brown L. Olive leaf extract attenuates cardiac, hepatic, and metabolic changes in high carbohydrate-, high fat-fed rats. The Journal of Nutrition. 2010;140(5):946-53.

[82] Manna C, Migliardi V, Golino P, Scognamiglio A, Galletti P, Chiariello M, et al. Oleuropein prevents oxidative myocardial injury induced by ischemia and reperfusion. The Journal of Nutritional Biochemistry. 2004;15(8):461-6.

[83] Visioli F, Galli C, Plasmati E, Viappiani S, Hernandez A, Colombo C, et al. Olive phenol hydroxytyrosol prevents passive smoking-induced oxidative stress. Circulation. 2000;102(18):2169-71.

[84] Andrikopoulos NK, Kaliora AC, Assimopoulou AN, Papageorgiou VP. Inhibitory activity of minor polyphenolic and nonpolyphenolic constituents of olive oil against In Vitro lowdensity lipoprotein oxidation. Journal of Medicinal Food. 2002;5(1):1-7.

[85] de la Puerta R, Gutierrez VR, Hoult JRS. Inhibition of leukocyte 5-lipoxygenase by phenolics from virgin olive oil. Biochemical Pharmacology. 1999;57(4):445-9.

[86] Cicerale S, Conlan XA, Sinclair AJ, Keast RSJ. Chemistry and health of olive oil phenolics. Critical Reviews in Food Science and Nutrition. 2008;49(3):218-36.

[87] Ramirez-Tortosa MC, Urbano G, López-Jurado M, Nestares T, Gomez MC, Mir A, et al. Extra-virgin olive oil increases the resistance of LDL to oxidation more than refined olive oil in free-living men with peripheral vascular disease. The Journal of Nutrition. 1999;129(12):2177-83.

[88] de Pasquale R, Monforte TM, Trozzi A, et al. Effects of leaves and shoots of Olea europaea L. and oleuropein on experimental hypercholesterolemia in rat. Plantes Medicinales et Phytotherapie. 1991;25:134-40.

[89] Bennani-Kabachi N, Fdhil H, Cherrah Y, et al. Effects of Olea europea var. oleaster leaves in hypercholesterolemic insulinresistant sand rats. Therapie. 1999;54:717-23.

[90] Perrinjaquet-Moccetti T, Busjahn A, Schmidlin C, Schmidt A, Bradl B, Aydogan C. Food supplementation with an olive 
(Olea europaea L.) leaf extract reduces blood pressure in borderline hypertensive monozygotic twins. Phytotherapy Research. 2008;22(9):1239-42.

[91] Susalit E, Agus N, Effendi I, Tjandrawinata RR, Nofiarny $\mathrm{D}$, Perrinjaquet-Moccetti T, et al. Olive (Olea europaea) leaf extract effective in patients with stage-1 hypertension: Comparison with Captopril. Phytomedicine. 2011;18(4):251-8.

[92] Conway J, Johnston J, Coats A, Somers V, Sleight P. The use of ambulatory blood pressure monitoring to improve the accuracy and reduce the numbers of subjects in clinical trials of antihypertensive agents. Journal of hypertension. 1988;6(2):111-6.

[93] Hansen K, Adsersen A, Christensen SB, Jensen SR, Nyman $\mathrm{U}$, Smitt UW. Isolation of an angiotensin converting enzyme (ACE) inhibitor from Olea europaea and Olea lancea. Phytomedicine. 1996;2(4):319-25.

[94] Fonollá J, Díaz-Ropero P, de la Fuente E, Quintela JC. MS358 One-month consumption of an olive leaf extract enhances cardiovascular status in hypercholesterolemic subjects. Atherosclerosis Supplements. 2010;11(2):182.

[95] Cherif N, Rahal M, Haouala B, Hizaoui F, Dargouth M, Gueddiche Z, Kallel G, Balansard K, Boukef K. A clinical trial of a titrated Olea extract in the treatment of essential arterial hypertension. Journal de Pharmacie de Belgique. 1996;51(2):69-71.

[96] Kendall M, Batterham M, Obied H, Prenzler PD, Ryan D, Robards K. Zero effect of multiple dosage of olive leaf supplements on urinary biomarkers of oxidative stress in healthy humans. Nutrition. 2009;25(3):270-80.

[97] Machowetz A, Poulsen HE, Gruendel S, Weimann A, Fitó M, Marrugat J, et al. Effect of olive oils on biomarkers of oxidative DNA stress in Northern and Southern Europeans. The FASEB Journal. 2007;21(1):45-52.

[98] Visioli F, Caruso D, Galli C, Viappiani S, Galli G, Sala A. Olive oils rich in natural catecholic phenols decrease isoprostane excretion in humans. Biochemical and Biophysical Research Communications. 2000;278(3):797-9.

[99] Scalbert A, Williamson G. Dietary intake and bioavailability of Polyphenols. The Journal of Nutrition. 2000; 130(8):2073S-85S.

[100] Ryan M, McInerney D, Owens D, Collins P, Johnson A, Tomkin GH. Diabetes and the mediterranean diet: A beneficial effect of oleic acid on insulin sensitivity, adipocyte glucose transport and endothelium.dependent vasoreactivity. QJM. 2000;93(2):85-91.

[101] Fuentes F, López-Miranda J, Sánchez E, Sánchez F, Paez J, Paz-Rojas E, et al. Mediterranean and low-fat diets improve endothelial function in hypercholesterolemic men. Annals of Internal Medicine. 2001;134(12):1115-9.

[102] Esposito K, Marfella R, Ciotola M, Di Palo C, Giugliano F, Giugliano G, et al. Effect of a mediterranean-style diet on endothelial dysfunction and markers of vascular inflammation in the metabolic syndrome. JAMA: The Journal of the American Medical Association. 2004;292(12):1440-6.

[103] Ruano J, Lopez-Miranda J, Fuentes F, Moreno JA, Bellido C, Perez-Martinez P, et al. Phenolic content of virgin olive oil improves ischemic reactive hyperemia in hypercholesterolemic patients. Journal of the American College of Cardiology. 2005;46(10):1864-8.
[104] Jiménez-Morales AI, Ruano J, Delgado-Lista J, Fernandez JM, Camargo A, López-Segura F, et al. NOS3 Glu298Asp polymorphism interacts with virgin olive oil phenols to determine the postprandial endothelial function in patients with the metabolic syndrome. Journal of Clinical Endocrinology \& Metabolism. 2011;96(10):E1694-702.

[105] de la Torre-Carbot K, Chávez-Servín JL, Jaúregui O, Castellote AI, Lamuela-Raventós RM, Fitó M, et al. Presence of virgin olive oil phenolic metabolites in human low density lipoprotein fraction: Determination by high-performance liquid chromatography-electrospray ionization tandem mass spectrometry. Analytica Chimica Acta. 2007;583(2):402-10.

[106] Visioli F, Colombo C, Galli C. Differential partitioning of antioxidants, including hydroxytyrosol, in human plasma and LDL: Implications for their antioxidant activity in vivo. Food Chemistry. 2012;132(1):499-501.

[107] Steinberg D, Witztum JL. Oxidized Low-Density Lipoprotein and Atherosclerosis. Arteriosclerosis, Thrombosis, and Vascular Biology. 2010;30(12):2311-6.

[108] Bagheri S, Ahmadvand H. Effects of olive leaves extract on LDL oxidation induced-CuSO4 in vitro. Clinical Biochemistry. 2011;44(13, Suppl):S345.

[109] Singal PK, Khaper N, Palace V, Kumar D. The role of oxidative stress in the genesis of heart disease. Cardiovascular Research. 1998;40(3):426-32.

[110] Madamanchi NR, Vendrov A, Runge MS. Oxidative stress and vascular disease. Arteriosclerosis, Thrombosis, and Vascular Biology. 2005;25(1):29-38.

[111] Scalbert A, Johnson IT, Saltmarsh M. Polyphenols: Antioxidants and beyond. The American Journal of Clinical Nutrition. 2005;81(1):215S-7S.

[112] Manach C, Williamson G, Morand C, Scalbert A, Rémésy C. Bioavailability and bioefficacy of polyphenols in humans. I. Review of 97 bioavailability studies. The American Journal of Clinical Nutrition. 2005;81(1):230S-42S.

[113] Collins AR. Assays for oxidative stress and antioxidant status: Applications to research into the biological effectiveness of polyphenols. The American Journal of Clinical Nutrition. 2005;81(1):261S-7S.

[114] Saija A, Trombetta D, Tomaino A, Lo Cascio R, Princi P, Uccella $\mathrm{N}$, et al. 'In vitro' evaluation of the antioxidant activity and biomembrane interaction of the plant phenols oleuropein and hydroxytyrosol. International Journal of Pharmaceutics. 1998;166(2):123-33.

[115] Goulas V, Papoti VT, Exarchou V, Tsimidou MZ, Gerothanassis IP. Contribution of flavonoids to the overall radical scavenging activity of olive (Olea europaea L.) leaf polar extracts. Journal of Agricultural and Food Chemistry. 2010;58(6):3303-8.

[116] Middleton E, Kandaswami C. Effects of flavonoids on immune and inflammatory cell functions. Biochemical pharmacology. 1992;43(6):1167-79.

[117] Carluccio MA, Siculella L, Ancora MA, Massaro M, Scoditti $\mathrm{E}$, Storelli $\mathrm{C}$, et al. Olive oil and red wine antioxidant polyphenols inhibit endothelial activation: Antiatherogenic properties of mediterranean diet phytochemicals. Arterioscler Thromb Vasc Biol. 2003;23(4):622-9.

[118] Dell'Agli M, Fagnani R, Mitro N, Scurati S, Masciadri M, Mussoni L, et al. Minor components of olive oil modulate 
proatherogenic adhesion molecules involved in endothelial activation. Journal of Agricultural and Food Chemistry. 2006;54(9):3259-64.

[119] Manna C, Napoli D, Cacciapuoti G, Porcelli M, Zappia V. Olive oil phenolic compounds inhibit homocysteine-induced endothelial cell adhesion regardless of their different antioxidant activity. Journal of Agricultural and Food Chemistry 2009; 57(9):3478-82.

[120] Hansson GK. Atherosclerosis: Cell biology and lipoproteins. Current opinion in lipidology. 1998;9(1):73-5.

[121] Petroni A, Blasevich M, Papini N, Salami M, Sala A, Galli C. Inhibition of leukocyte leukotriene B4 production by an olive oil-derived phenol identified by mass-spectrometry. Thrombosis Research. 1997;87(3):315-22.

[122] Leger CL, Kadiri-Hassani N, Descomps B. Decreased superoxide anion production in cultured human promonocyte cells (THP-1) due to polyphenol mixtures from olive oil processing wastewaters. Journal of Agricultural and Food Chemistry. 2000;48(10):5061-7.

[123] Leger CL, Carbonneau MA, Michel F, Mas E, Monnier L, Cristol JP, et al. A thromboxane effect of a hydroxytyrosol-rich olive oil wastewater extract in patients with uncomplicated type I diabetes. Eur J Clin Nutr. 2005;59(5):727-30.

[124] Miles EA, Zoubouli P, Calder PC. Differential antiinflammatory effects of phenolic compounds from extra virgin olive oil identified in human whole blood cultures. Nutrition. 2005;21(3):389-94

[125] Trefiletti G, Togna RA, Latina V, et al. 1-Phenyl6,7-dihydroxy-isochroman suppresses lipopolysaccharideinduced pro-inflammatory mediator production in human monocytes. Anglais. 2011;106(1):4.

[126] Beckman JS, Koppenol WH. Nitric oxide, superoxide, and peroxynitrite: The good, the bad, and ugly. American Journal of Physiology-Cell Physiology. 1996;271(5):C1424-C37.

[127] de la Puerta R, Domínguez MEM, Ruíz-Gutíerrez V, Flavill JA, Hoult JRS. Effects of virgin olive oil phenolics on scavenging of reactive nitrogen species and upon nitrergic neurotransmission. Life Sciences. 2001;69(10): 1213-22.

[128] Griendling KK, Sorescu D, Ushio-Fukai M. NAD(P)H oxidase: Role in cardiovascular biology and disease. Circulation Research. 2000;86(5):494-501.

[129] Kusaka I, Kusaka G, Zhou C, Ishikawa M, Nanda A, Granger DN, et al. Role of AT1 receptors and NAD $(\mathrm{P}) \mathrm{H}$ oxidase in diabetes-aggravated ischemic brain injury. American Journal of Physiology-Heart and Circulatory Physiology. 2004;286(6):H2442-H51.

[130] Hwang J, Ing MH, Salazar A, Lassègue B, Griendling K, Navab M, et al. Pulsatile versus oscillatory shear stress regulates NADPH oxidase subunit expression. Circulation Research. 2003;93(12):1225-32.

[131] Byrne JA, Grieve DJ, Bendall JK, Li J-M, Gove C, Lambeth JD, et al. Contrasting Roles of NADPH oxidase isoforms in pressure-overload versus angiotensin II-induced cardiac hypertrophy. Circulation Research. 2003;93(9): 802-5.

[132] Sorescu D, Weiss D, Lassègue B, Clempus RE, Szöcs K, Sorescu GP, et al. Superoxide production and expression of nox family proteins in human atherosclerosis. Circulation. 2002;105(12):1429-35.

[133] Rajagopalan S, Kurz S, Munzel T, Tarpey M, Freeman BA, Griendling KK, et al. Angiotensin II-mediated hypertension in the rat increases vascular superoxide production via membrane NADH/NADPH oxidase activation. Contribution to alterations of vasomotor tone. The Journal of Clinical Investigation. 1996;97(8):1916-23.

[134] Leiro J, Alvarez E, Arranz JA, Laguna R, Uriarte E, Orallo F. Effects of cis-resveratrol on inflammatory murine macrophages: Antioxidant activity and down-regulation of inflammatory genes. Journal of Leukocyte Biology. 2004; 75(6):1156-65.

[135] Orallo F, Álvarez E, Camiña M, Leiro JM, Gómez E, Fernández P. The possible implication of trans-resveratrol in the cardioprotective effects of long-term moderate wine consumption. Molecular Pharmacology. 2002;61(2):294-302.

[136] Deby-Dupont G, Mouithys-Mickalad A, Serteyn D, Lamy M, Deby C. Resveratrol and curcumin reduce the respiratory burst of Chlamydia-primed THP-1 cells. Biochemical and Biophysical Research Communications. 2005;333(1):21-7.

[137] Dal-Ros S, Zoll J, Lang A-L, Auger C, Keller N, Bronner $\mathrm{C}$, et al. Chronic intake of red wine polyphenols by young rats prevents aging-induced endothelial dysfunction and decline in physical performance: Role of NADPH oxidase. Biochemical and Biophysical Research Communications. 2011;404(2):743-9.

[138] Ying CJ, Xu JW, Ikeda K, Takahashi K, Nara Y, Yamori Y. Tea polyphenols regulate nicotinamide adenine dinucleotide phosphate oxidase subunit expression and ameliorate angiotensin II-induced hyperpermeability in endothelial cells. Hypertension research: Official Journal of the Japanese Society of Hypertension. 2003;26(10):823-8.

[139] Steffen Y, Gruber C, Schewe T, Sies H. Mono-O-methylated flavanols and other flavonoids as inhibitors of endothelial NADPH oxidase. Archives of Biochemistry and Biophysics. 2008;469(2):209-19.

[140] Artajo LS, Romero MP, Motilva MJ. Transfer of phenolic compounds during olive oil extraction in relation to ripening stage of the fruit. Journal of the Science of Food and Agriculture. 2006;86(4):518-27.

[141] Japón-Luján R, Luque de Castro MD. Superheated liquid extraction of oleuropein and related biophenols from olive leaves. Journal of Chromatography A. 2006;1136(2): 185-91.

[142] Japón-Luján R, Luque-Rodríguez J, Luque de Castro M. Multivariate optimisation of the microwave-assisted extraction of oleuropein and related biophenols from olive leaves. Analytical and Bioanalytical Chemistry. 2006;385(4):753-9.

[143] Japón-Luján R, Luque-Rodríguez JM, Luque de Castro MD. Dynamic ultrasound-assisted extraction of oleuropein and related biophenols from olive leaves. Journal of Chromatography A. 2006;1108(1):76-82.

[144] Briante R, La Cara F, Febbraio F, Patumi M, Nucci R. Bioactive derivatives from oleuropein by a biotransformation on Olea europaea leaf extracts. Journal of Biotechnology. 2002;93(2):109-19.

[145] Briante R, Patumi M, Terenziani S, Bismuto E, Febbraio F, Nucci R. Olea europaea L. Leaf Extract and Derivatives: 
Antioxidant Properties. Journal of Agricultural and Food Chemistry. 2002;50(17):4934-40.

[146] Meirinhos J, Silva BM, Valentão P, Seabra RM, Pereira JA, Dias A, et al. Analysis and quantification of flavonoidic compounds from Portuguese olive (Olea Europaea L.) leaf cultivars. Natural Product Research. 2005;19(2):189-95.

[147] Mourtzinos I, Salta F, Yannakopoulou K, Chiou A, Karathanos VT. Encapsulation of olive leaf extract in $\beta$ Cyclodextrin. Journal of Agricultural and Food Chemistry. 2007;55(20):8088-94.

[148] Aouidi F, Ayari S, Ferhi H, Roussos S, Hamdi M. Gamma irradiation of air-dried olive leaves: Effective decontamination and impact on the antioxidative properties and on phenolic compounds. Food Chemistry. 2011;127(3):1105-13.

[149] Scognamiglio M, D'Abrosca B, Pacifico S, Fiumano V, De Luca PF, Monaco P, et al. Polyphenol characterization and antioxidant evaluation of Olea europaea varieties cultivated in Cilento National Park (Italy). Food Research International. 2012;46(1):294-303.

[150] Ryan D, Prenzler PD, Lavee S, Antolovich M, Robards $\mathrm{K}$. Quantitative changes in phenolic content during physiological development of the olive (Olea europaea) Cultivar Hardy's Mammoth. Journal of Agricultural and Food Chemistry. 2003;51(9):2532-8.
[151] Benavente-García O, Castillo J, Lorente J, Ortuño A, Del Rio JA. Antioxidant activity of phenolics extracted from Olea europaea. Lleaves. Food Chemistry. 2000;68(4):457-62.

[152] Hayes JE, Allen P, Brunton N, O'Grady MN, Kerry JP. Phenolic composition and in vitro antioxidant capacity of four commercial phytochemical products: Olive leaf extract (Olea europaea L.), lutein, sesamol and ellagic acid. Food Chemistry. 2011;126(3):948-55.

[153] Le Floch F, Tena MT, Rios A, Valcárcel M. Supercritical fluid extraction of phenol compounds from olive leaves. Talanta. 1998;46(5):1123-30.

[154] Lee O-H, Lee B-Y, Lee J, Lee H-B, Son J-Y, Park C-S, et al. Assessment of phenolics-enriched extract and fractions of olive leaves and their antioxidant activities. Bioresource Technology. 2009;100(23):6107-13.

[155] Makris DP, Boskou G, Andrikopoulos NK. Polyphenolic content and in vitro antioxidant characteristics of wine industry and other agri-food solid waste extracts. Journal of Food Composition and Analysis. 2007;20(2):125-32.

[156] Ryan D, Antolovich M, Herlt T, Prenzler PD, Lavee $\mathrm{S}$, Robards K. Identification of phenolic compounds in tissues of the Novel Olive Cultivar Hardy's Mammoth. Journal of Agricultural and Food Chemistry 2002; 50(23): 6716-24. 